\title{
CAUSES OF DISEASE IN YOUNG SALMONOIDS
}

From BULLETIN OF THE BUREAU OF FISHERIES, Volmme XXVII, I908

Proceedings of the Fourth Intemational Fishery Congress : Washington, I 908

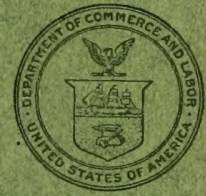

(3)

WASHINGTON : : : : : : GOVERNMENT PRINTING OFFICE : : : : : 1910 


$$
\widetilde{6}
$$




$$
\text { - }
$$





\section{CAUSES OF DISEASE IN YOUNG SALMONOIDS}

From BULLETIN OF THE BUREAU OF FISHERIES, Volume XXVIII, I908

Proceedings of the Fourth International Fishery Congress : : Washington, 1908

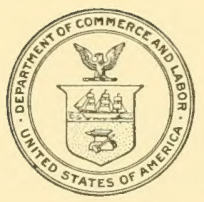

WASHINGTON : : : : : : GOVERNMENT PRINTING OFFICE $: \quad: \quad: \quad: \quad: \quad 1910$ 
BUREAU OF FISHERIES DOCUMENT NO. 689

Issued April, 1910

$A^{\circ} 301910$ 


\section{CAUSES OF DISEASE IN YOUNG SALMONOIDS}

\section{*}

By Eugene Vincent

Fish Culturist, Aquarium of the Trocadero, Paris

Paper presented before the Fourth International Fishery Congress

held at Washington, U. S. A., September 22 to 26, 1908 


\section{CONTENTS.}

\section{2}

Page.

Diseases of the gills . . .

Faulty hatching equipment and conditions...... 909

Measures of prevention _. _

Curative measures_._.

An epidemic of "staggers" in rainbow trout fry 908 


\title{
CAUSES OF DISEASE IN YOUNG SALMONOIDS.
}

\author{
By EUGENE VINCENT, \\ Fish Culturist, Aquarium of the Trocadero, Paris. \\ $*$ \\ [Translated from the French.]
}

The common trout and its varieties are especially subject to disease of the gills, and other salmonoids likewise are not exempt from it. Such disease consequently presents great difficulty to fish culturists, who must find means of combating it. Another frequent trouble is the epidemic which may be called "staggers." The effective measures in both cases are those of prevention rather than attempt to cure; and the best means of prevention is perfect cleanliness of equipment, from the beginning of the hatching period throughout. To maintain the necessary cleanliness, however, is a question of style of apparatus as well as unremitting care.

\section{DISEASES OF THE GILLS.}

\section{FAULTY HATCHING EQUIPMENT AND CONDITIONS.}

As fish culturists well know, the styles of apparatus for incubating eggs of the salmon species are very numerous. In France the most common equipment is the Coste trough and its derivatives, consisting of a kind of rectangular zinc box 0.50 to 0.60 meter long, 0.25 meter wide, and 0.20 meter high, with two partitions of perforated sheet iron, the one serving to admit the water from below, the other allowing it to pass out from above. Into this box is set a glass grille of dimensions to fit.

I have heard much in praise of all varieties of apparatus, but I have heard little concerning their disadvantages and dangers. It is of these latter that I shall speak.

First of all, I consider the equipment bad which does not allow the fish culturist to see what is taking place below the grilles on which the eggs are resting or permit of cleaning without disturbing the eggs.

We are told that there are currents of water in this apparatus, which receive as much as one-half liter of water per minute. There can be no currents of water in these troughs, however, especially in those with partitions; there is, to be sure, a change of water, but there is no current which would bring about a flow throughout, and this may be easily shown by putting into the water coloring matter or thin strips of paper. And it is precisely the absence 
of this current which determines and creates the dangers to which the eggs and the fry are exposed-this, first, because the quantity of water supplied to the apparatus is not sufficient; second, because all obstacles, as the partitions in the apparatus, operating to prevent a current, become a hearth of infection of all kinds, by the corners they make; third, because of the very dimensions and the shape of these troughs; and fourth, the visible proof, because there are found in these troughs and in the rearing troughs fry large enough to be able to maintain an equilibrium, yet lying on their sides, with gills compressed against the bottom of the basin and in contact with the slimy ooze of the bottom. If the fish makes a movement, it is only to fall back on the other side, so that the gills are by turn infected with noxious substances from the bottom, which can not be seen and cleaned as it ought to be.

The greatest cleanliness is always necessary in fish culture, and it must be made attainable. Let us see, without being pessimistic, what the conditions most often are.

The fish-cultural apparatus found on the market has not all been invented by fish culturists having a knowledge of this science. The manufacturer sells apparatus the advantages of which he extols with the aid of so-called fishcultural tracts (though in reality they are not such), and the inexperienced purchaser establishes his business immediately, with confidence of success.

If he buys eyed eggs, he will not have the same difficulties as the man who collects the eggs himself. Let us take the latter for example. The eggs are placed on the grilles and the grilles in the troughs, all these things being more or less well washed, but the wooden screens can not be put in the flame so as to destroy all germs. Then there may be among the eggs excretions of fishes that may have fallen in the stripping, or there may be shells of broken eggs, all of which may drop through the grille to the bottom of the trough, to be left there during the entire period of incubation, together with any dead eggs that may have slipped between the glass bars.

If the water contains sediment, this will be deposited on the bottom of the trough and will remain there. The fish culturist has been told that all he has to do is to take out the few dead eggs and await the hatching of the others before cleaning out his apparatus. Water is not the same everywhere; all has its advantages and its disadvantages; in France the incubation takes place in water the temperature of which varies during this period from $6^{\circ}$ to $12^{\circ} \mathrm{C}$. (I do not refer to the mountain region), and often the incubation period lasts from forty-five to fifty days. It is well known that some eight days before the first hatching some eggs will burst. Their contents, escaping, spread over the eggs in long filaments which attach themselves to the grill, pass through it, go to the bottom, increase the amount of sediment, and encourage the invasion of Saprolegnia. 
The unfertile eggs are not taken out, and the first filament of fungus may not be seen on an egg that is in a corner of the grill. But later the eggs may be covered with this delicate down, and although something might still be done for the embryos whose breathing is thus interfered with, even the flow of water has not been increased since the eye spots appeared, and so the fungus establishes itself.

The hatching time is now at hand, and may last, in water having a temperature of $10^{\circ}$, some ten or twelve days, and sometimes more. Until it is over there is no thought of placing the fry in a cleaner place. As the fry hatch they fall, like the shells of their eggs, to the bottom of the trough, on a soft velvet composed of the flourishing Saprolegnia.

And these unfortunate fry, the gills of which have never ceased being in forced contact with all the impurities and disease germs which line the bottom of the trough, are now to be disturbed in this water, the sediment in which will be visible to the operator when he shakes or moves the trough. Nor is it only the breathing apparatus which suffers, but the entire fish, for its body receives shocks and wounds, inviting the fungus, and the mouth particularly becomes infected.

The disease then has secured its hold. It is not perceived, for the operator believes that he has done all that is necessary by cleaning the fry at the close of the hatching. They may have been replaced in the same trough after giving the latter a hasty cleaning, for maybe there was no other at hand. Fry from two different troughs may have been put together without thought of the imprudence of this. The lots are then of different ages by ten to twelve days, and they are a little crowded, there being 2,000 to 2,500 in those little troughs without any increase of the flow of water-for how long? They will be fed in a month, perhaps six weeks. In the meantime there is amusement in finding a few monstrosities among them. These die from day to day and the yolk sac sheds its contents, which adhere to the bottom and form white spots which occasion no alarm. The Saprolegnia finds again a favorable bed for development.

The oldest and most robust of the fry, endeavoring to move about a little, reach a corner of the trough, where they crowd against each other. By their swimming movements they form in this corner a small current, or more exactly, a slight motion of the water sufficient to maintain them in equilibrium on their yolk sacs facing this small partial current. As soon as the fry ceases to feel this current it can not maintain itself on its yolk sac and falls on its side. Is it no longer so strong? No; that is not the reason-it is the motion of the water which is lacking and which does not exist in the trough in any other spot except where the fry make it themselves. The proper motion of the water is created by a device of mine which I shall describe, a siphon outlet system; but for the present I say that the eggs in incubation were not given a current sufficient to wash them, facilitate the exchange of gases, and keep them from being covered 
with a thin layer of sediment. I maintain that thus the embryos also steffered, and I am sure that it is in this way the fry contract the disease of the gills.

Such is the origin of the disease which manifests itself in young fish in swollen gills, impregnated with dirt and bulging so much as to push out the operculum. The fish are seen to weaken and turn dark in color and then die, at first in small numbers, but increasing to an almost complete mortality. It may be justly assumed that those which escape are those which hatched last and have not been so long in contact with the deposit on the bottom of the trough. This terrible disease may not manifest itself among the young fish until the age of five to six weeks.

In addition to the cause I have named for the origin of this disease of the gills, it is sometimes due to placing too much food into the rearing troughs. The coagulated blood, spleen pulp, pulp of liver, etc., becoming diluted, render the water at times so tinted that it is impossible to see through it. The gills are impregnated with putrefiable matter, which soon gives rise to this terrible epidemic, especially if the water is not aerated and frequently changed. Lastly, a great number of fry in a small space, not receiving a sufficient quantity of water, acquire the disease of the gills by atrophy, as may be easily recognized by the small size and emaciation of the fish.

\section{MEASURES OF PREVENTION.}

As stated at the outset, the remedy for this disease is prevention, which involves the utmost care on the part of the attendant, with also the form of equipment which shall permit of the most perfect cleanliness. I will indicate the means I have employed and consider essential.

I. Discard all apparatus that does not allow the interior to be examined. It must be possible to see under the grilles on which the eggs are placed, and, if necessary, to clean the bottom of the trough without interfering with the incubation process.

2. Use an equipment which will permit of retaining the fry therein after the hatching is over. Discard the wooden grille frame for one of metal and replace the glass tubes with solid glass rods.

3. Have an ample supply of water in proportion to the number of eggs in the trough, and create currents to reach every part. Increase the supply of water, if possible, as soon as the eye spots appear in the egg.

4. Do not crowd the eggs on the grille. Take out the dead eggs each day. Do not refill the spaces left by the removal of dead eggs. These, taken out to prevent their bursting in the trough, will now give more space to the developing eggs. Take out any eggs containing monstrosities.

5. Give a thorough cleaning both to grilles and troughs when the eggs are ready to hatch, so that the fry may fall to the bottom of the trough without danger to their gills. A hand siphon cleaner ${ }^{a}$ should be used for the trough.

$a$ Vincent E.: Devices for use in fish hatcheries and aquaria. Proceedings Fourth, International Fishery Congress, Bulletin U. S. Bureau of Fisheries, vol. xxvin, 1908, p. 1030. 
6. If the hatching equipment is not adapted for retaining the fry, transfer each day's hatch, classifying by age, to thoroughly cleaned troughs, with such number to each trough as may be held for five or six weeks. In making the transfer use a syringe of $\mathrm{r} / \mathrm{t}$ to $\mathrm{I} / 2$ liters capacity, with a tube of $0.0 \mathrm{I} 7$ meter diameter, so that the gills and yolk sac of the fry shall not be compressed. Do not keep the fry in darkness or obscurity; daylight is better for them. Eliminate monstrosities. Change the water every day, the siphon outlet ${ }^{a}$ serving also as an auxiliary cleaner, since it creates currents in the troughs. Dispose the intake at a point to produce a longitudinal motion of water.

7. I feed the fry, to aid them in developing, beginning four days after hatching. This has been my practice for some six years, and I have found it good. I clean the troughs every day with a brush, called codfish tail, and take out any remnants of food which the siphon outlet has not carried off. When the fish are some five or six weeks old I put them in large troughs, the cleaning of which is simpler, and here I feed them with beef spleen placed in small wire baskets fixed at about mid depth of the trough, this to prevent the fish from seeking food at the bottom and so that less shall be wasted.

It is difficult in a large establishment to have really filtered water. No filter at all is better than a bad one.

Various devices of mine described elsewhere (op. cit.) have proved an aid to the realization of the necessary cleanliness in fish hatching. I have adopted also a combination trough, to be used both for the eggs during the incubation period and for the fry afterwards, thus avoiding the disturbance and injury of a transfer of the very young and delicate fish, while at the same time offering the advantages of the currents they need, besides facilities for perfect cleanliness. This trough is of cement and measures inside 1.5 meters long, 0.3 meter deep, and 0.35 meter wide. The shape is such as to aid in cleaning, having no angles, but curves only. The size is sufficient to accommodate two grilles and the siphon outlet apparatus already referred to. The interior is especially designed, after repeated experiment, to provide currents suitable for the eggs during incubation and later for the fry, to give the latter means of equilibrium and also supply them with food in a natural manner. The particles of food are always in motion in this trough. The model belongs to the firm of Leune, Rue Cardinal Lemoine, 28 bis, Paris.

It is important for the fry to be in equilibrium, and not lying with gills against the bottom, even though the troughs be clean, a condition which is attainable if there be a current, but not otherwise. As soon as there is the smallest motion giving the sensation of a current even the very young fry will respond to it. This may be tested by the simple experiment of using a syringe 
in the water close to the fry. The little heads at once turn toward the current, the bodies righting themselves upon the yolk sac, and this equilibrium is maintained so long as the current continues. When it fails the fry fall back on their sides.

It is suitable currents that also make it possible to feed the very small fry without danger of disease. Even before the yolk sac has begun to diminish they will face the currents and make efforts to catch small particles of food passing some three or four centimeters above them. I have shown this very interesting and amusing sight in aquaria, and it is because of such experiments that I insist the fry shall be fed when four days old. At the end of ten or twelve days, in water having a temperature of about $10^{\circ}$, will be observed the occurrence above noted, and a few days later these fry, developed and strengthened by the food they have had, but still with their yolk sac, may be seen swimming progressively. The fry should not be kept in darkness. They must be able to see their food to get it.

\section{CURATIVE MEASURES,}

With the precautions I have enumerated the fry will not be affected with the gill disease. If, however, I should find myself confronted with it I would reduce the number of fry by half; I would place them in semiobscurity and would give them no food for several days, in order not to put into the water the slightest substance for putrefaction, and keep the gills free of any organic matter due to the food or its remains. I would have well-aerated water and take care not to leave any dead fish in the troughs. Such would be the treatment to be given - a thorough cleaning from the beginning of the disease. But I do not guarantee that I could save fry which were seriously affected.

The gills are very sensitive to the disease, and their impregnation with organic matter, be it only a temporary one, causes death. I have been a professional fisherman, and all fishermen know very well that fishes caught during the first days of rising water never live, can not live, even if they are taken with the most inoffensive of fishing devices, and this is so because their gills are filled with organic matter and sediment which rising water always carries along. Three or four days after the beginning of the rise of water the gills are slowly cleaned and the fishes live.

\section{AN EPIDEMIC OF "STAGGERS" IN RAINBOW TROUT FRY.}

The brood trout in this case weighed about four ounces and laid eggs now for the second time. The eggs were placed in filtered spring water at a temperature of $9^{\circ}, 10^{\circ}$, and even $\mathrm{II}^{\circ}$, and incubation lasted forty days. The greatest hatch took place on March 14, I906, lasting two days. The small fry were placed in nonfiltered water, where they were kept from March 16 to April I4. 
These fry were fed regularly every day, from the fourth day after hatching, with pulp of beef spleen, first crushed in a mortar, then passed through a horsehair sieve. Somewhat later I contented myself with rubbing the spleen pulp, which was somewhat diluted, in the trough and between my hands, the fry eating this very well. On April 20, i. e, about thirty-five days after hatching, the trout, now in a pond, were eating pulp which I did not crush, but placed in a small basket suspended between two currents in the pond.

The pond was supplied with river water, of a temperature of $12 \frac{1}{2^{\circ}}$. It was 7 meters in length, 2.5 meters in width, and I.8 meters in depth. The flow of water was io liters per minute from the town supply. There were 9,000 fish. Time passed and these trout, having in only one and one-half months reached a size varying between 0.032 and 0.035 meter long, were well and healthy.

We had reached April 24 when two things happened to cause me apprehension. The allowance of food given to these trout had been gradually diminished, and on the other hand the water flowing into the basin, at the rate of ro liters per minute, passed through a gravel filter, which did not inspire any confidence in me.

Before reaching this filter the water passed through three decantation basins, each containing about ro cubic meters, then it rose between two walls, where it met a filter composed of medium pebbles, a layer of 0.25 meter, then a similar layer of gravel, then another layer 0.3 meter thick of finer gravel, then coarse sand O.I 5 meter thick, and finally a layer of O.I 5 meter of fine sand. These layers of gravel and sand were separated from each other by suitable sheets of metal.

Being able to see from the side into the interior of this filter, through glass panes 0.027 meter thick and I meter high, I ascertained that the filter was in reality dirty, the dirt obstructing the passage of the water through the gravel, so that the latter was kept back and rose in the basins of decantation. (It is well known that a filter made of gravel and sand does not operate well until it collects a surface layer of dirt, but on the other hand, as is not so well known, it is not necessary to wait until the surface is dirty to have the under layers cleaned.) I saw then that at hundreds of places organic matter formed with the gravel a more or less compact mass, and mold was to be found everywhere. This organic matter, this mold, consumed the oxygen contained by the water to the detriment of the welfare of the rainbow trout.

I foresaw danger in this growth of Saprolegnia of all kinds, and the multitudes of small animal life, some of it almost invisible to the naked eye.

The water was cut off and the upper part of the filter was partly cleaned; not thoroughly, however, as both time and space are needed for the washing 
of all the gravel and all the sand, the layers of which lay flat on an area of 2.4 meters by 0.6 meter.

The filter, in short, was not sufficiently cleaned, the water was turned on again, and not sufficient note was made of the fact that it was the 8 th of May and the river water at a temperature of $17^{\circ}$, the first result of which would be a sudden mortality among the trout. This happened, too. From May 8 to May 17 the water was maintained at this temperature, and on the morning of the last day I noticed some 30 trout dead in the pond, while the others were being carried to the grating at the outlet. Most of the fish turned over and over and made pirouettes, then jumped into the mass of water as if to cross it in one movement, but they fell exhausted and dropped to the bottom. About I I o'clock in the morning 300 trout were dead.

The fish had "the staggers." In two days they grew somewhat dark, then they began to weaken, swam with difficulty, and could no more maintain a horizontal position; their behavior was abnormal, and they finally died. All of the trout did not show the weakening, but fell to the bottom of the pond and succumbed after opening their gills convulsively two or three times.

I gathered the dead trout with a net and counted $\mathrm{r}, 200$ of them. That evening there were more on the bottom of the pond, and by the evening of the next day the mortality was almost complete. The remainder living was an insignificant number. I believe that 160 were placed in spring water, and out of these I 60 only about Ioo were saved.

This mortality had been caused by the imperfect action of the gravel filter and by its dirtiness, by the fermentation of the organic matter which the filter had retained when from April 24 the temperature of the water, $12^{\circ}$, rose to $17^{\circ}$ about May Io. The cleaning of the upper layers of fine sand of the filter gave free passage to the Saprolegnia, the mycelium of which abounded in the lower parts or layers of gravel, and all this infection invaded the basin, with the effect of all as just described.

In order to remedy this at least partially, if there is no spring water at one's disposition, it is better not to use any filter than to use such as this. The great quantity of water necessary in a fish-culture establishment makes it difficult to obtain a perfect filter. It might be well to use water from a river, easily aerated if the pond is lower than the river.

The best means of doing without a filter would be to keep a small fry trough very clean, so as to be susceptible only to disease or an infection coming from without, which is much at best. In order to attain this practical result, a siphon-outlet system, of a kind such as I have devised (op. cit.), should be installed. 



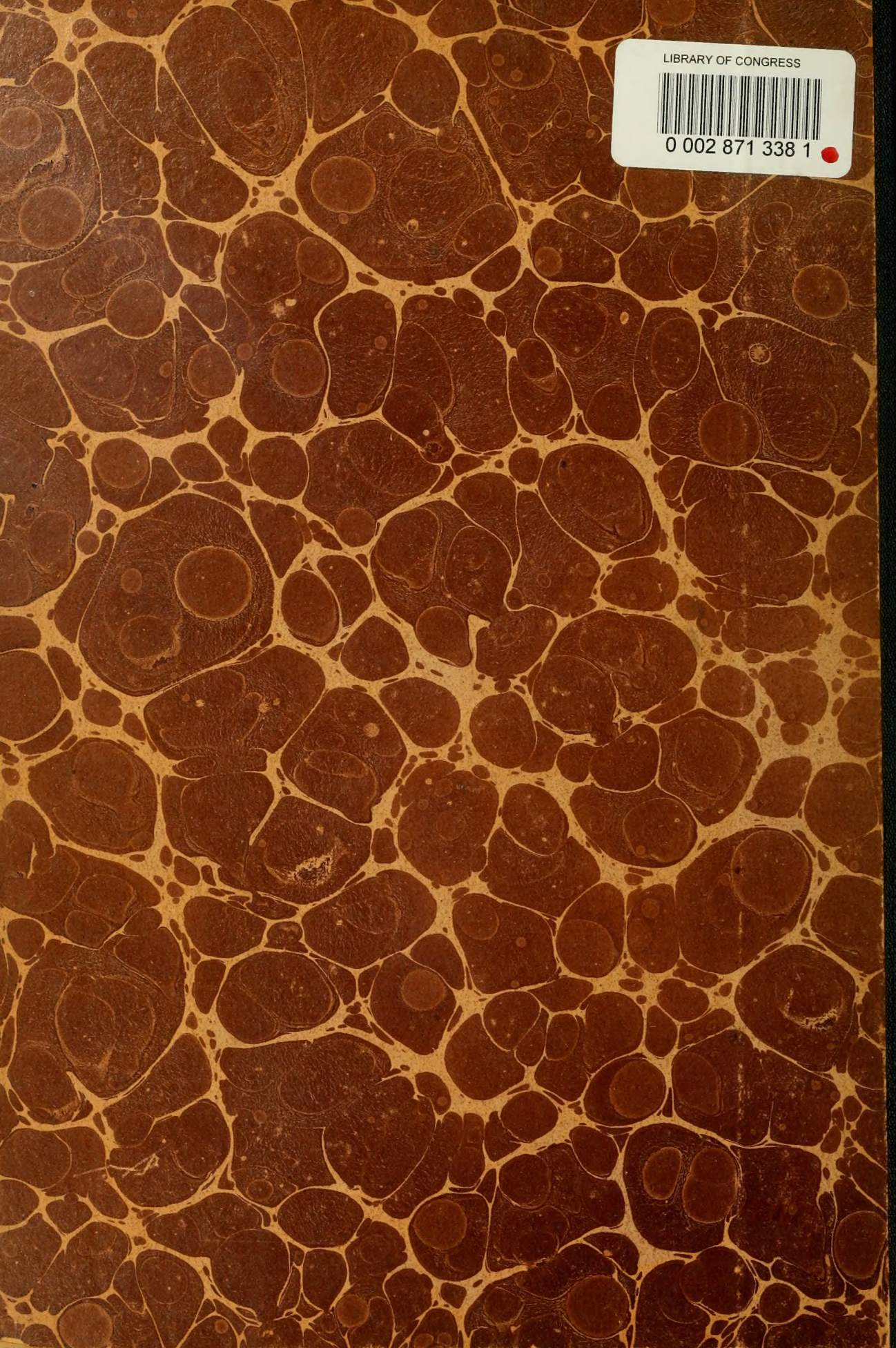

